\title{
Management and Development of ecotourism in the nature reserve under the context of sustainable development
}

\author{
Lei BAO \\ Tangshan Vocational College of Science And Technology \\ Tangshan, Hebei,China
}

\begin{abstract}
This article from the management and development of ecotourism in the nature reserves analyzes the current problems of the management and development of ecotourism nature in china and offers theories of management and countermeasures aimed at these problems. With people's living standard improved, the overall quality increasingly enhanced, people are willing to go to Protected Areas to experience the natural ecological resources, receive environmental education and acquire natural knowledge. Therefore, the development and management of ecotourism is particularly important.
\end{abstract}

Keywords- nature reserve; ecotourism; management; development

\section{INTRODUCTION}

All business activities of ecotourism in the nature reserve should adhere to the principle that environmental resources should be protected, which are established on the basis of Environmental Resource Protection and they all should present scientific organizational management and protection for natural environment and human landscape to improve and beautify the environmental resources in nature reserve.

The core of Nature Reserve ecotourism is to adhere to the principle that it can acquire optimal economic benefit while keeping protecting environmental resources. The development of ecotourism hopes to acquire economic benefit by using the well environment and also to build up a win-win and healthy development pattern.

The ecotourism development of Nature Reserve must adhere to the guiding principle of sustainable development. In view of eco-tourism resources of Nature Reserve being a special resource that differs from general tourism resources, it possesses original and integrity value, which has direct influence on the economic benefit of tourist attractions. Clearly, development and protection are both cores of sustainable tourism development, which is consistent with the development and protection of nature reserve.

\section{THE CURRENT SITUATION AND PROBLEMS OF ECOTOURISM MANAGEMENT OF NATURE RESERVE.}

\section{A. Blind developing and using ecotourism resources}

The rising ecotourism and regardless of the cost cause to inflated profits, which prompts that many nature reserves increasingly mark ecotourism as a new economic growth point to be cultivated and supported.

\section{B. Overloading tourists}

Regardless of carrying capacity of protected areas, some reserves merely over emphasize economic benefits but ignore protect ecotourism environment and analysis the capacity of environment before being developed, leading to the phenomenon that there are crowded tourists during the peak of traveling.

\section{The lack of general planning and talents on ecotourism} management

At present, China hasn't acquired comprehensive research achievements combining with domestic situation, especially the management level of protected areas. From developing to managing, it generally lacks well understanding on the true meaning of "ecotourism" and didn't make a detailed traveling planning, or even having detailed plans but haven't been implemented well.

\section{The barrier of green marketing}

Ecotourism products marked as a higher level than general green products have a higher price with high costs. Because of the weak sense of environmental protection from people, most of them choose the general mass tourism, which makes barriers to the green marketing.

\section{THE DEVELOPMENT SITUATION AND PROBLEMS OF NATURE RESERVE}

Our nature reserves are generally divided from representative natural ecosystems, land, water or sea natural concentrated distribution of rare and endangered wildlife species of special significance, which all should be set aside a certain areas to be protected and managed. It has generally formed a diverse network of nature reserve filled with more reasonable regional distribution and has made a remarkable protective effect. According to the study "in the Chinese national key protected nature reserve wildlife resources investigation" (2005) from State Environmental Protection Administration, China's

$84.84 \%$ of the national key protected wild animals and $86.27 \%$ of the national key protected wild plants are different degrees of distribution in nature reserves that has become the last habitat of rare and endangered species.

Serious shortage of funding results in low levels of protected area management and research. In recent years, the quantity of nature reserves has grown rapidly, but the funds 
from state putting into nature reserves is very limited, so they almost unable to carry out the management and protection and research work expect payment of management salaries.

Complex contradiction is between development and construction projects and nature reserves. In recent years, with the gradually deepening of range of economic activities, some of the major construction projects have extended into the nature reserve, leading to passive adjustment of protected areas and protected objects severely affected. At the same time, community residents in nature reserves over exploitative natural resources.

Regulatory system is not perfect. Nature Reserves Regulations of People's Republic of China currently is particular special laws and regulations promulgated on nature reserves, which have difficulties to meet the requirements of the development of the current Nature Reserve, urgently relevant laws and regulations promulgated nature reserve system method to be introduced.

\section{MAJOR PROBLEMS AND COUNTER MEASURES OF ECOTOURISM BEING ON THE BASIS OF SUSTAINABLE DEVELOPMENT.}

Although protection is the core of ecotourism of nature reserves, it will boring a series of influence on environment of nature reserves as soon as they haven't been managed strictly. In recent years, due to the rapid development of the domestic ecotourism, vague tourism awareness and understanding still exist in many areas which are over concerned with mutual beneficial relations between protected areas and the disputes on concept of them and ignore the strict principles and norms in the real operation and also only chase economic interests, but finally they aren't up to the standard of ecotourism. According to incomplete estimate that there are currently more than $22 \%$ of the nature reserves where environment have been destroyed due to carrying out "ecotourism", and there are also water pollution, air pollution and noise pollution in vary degrees.

\section{A. Normalizing countermeasures of ecotourism of nature reserves.}

China is one of most eco-tourism resource-rich countries in the world, while our country is facing serious shortage of funds and low management level, and community economic level of the vast majority of protected areas is still very backward, however carrying out scientific and standardized ecological tourism is exact important and possible measures to solve the backward situation.

Normalize ecotourism planning and environmental impact and strengthen supervision and management and monitoring. Firstly, Nation should make ecotourism standards as soon as possible and establish strict market assessment and certification system, forming a comprehensive reporting, planning, construction, operation, supervision, management and monitoring system from the system and the laws and regulations to improve the management system of ecotourism of nature reserves.

Adhering to protected area management and eco-tourism operating with the principle of separation. At present, many nature reserves are directly run by reserve managers, which can easily lead to only pursuit of economic interests while ignoring the protection of nature reserves. Management relations in the region should properly treat the relationship within ecotourism and initiative operations phase separation, consciously identifying as ecotourism supervisor and supervising strictly development and operation of ecotourism from the perspective of resource conservation.

Strictly controlling the ecotourism environmental capacity can eliminate the impact from environmental pollution on protected areas. Any nature reserve has its specific ecological carrying capacity, and too much interference outside and visitors will destroy the main object protected, natural landscape and various environmental factors.

Increasing the degree of community participation, it strengthen the educational function of ecological tourism. Holding trains, seminars and other ways can improve the environmental protection zone concept of community residents and absorb residents who have certain ecological protection skills to participate in eco-tourism, in addition to actively participating in services, tour guide, etc., but also make some excellent participation decision-making and management of eco-tourism.

\section{THE RELATIONSHIP BETWEEN ECOTOURISM SUSTAINABLE DEVELOPMENT AND ECOLOGICAL ENVIRONMENTAL MANAGEMENT.}

The tourism sustainable tourism development system is consist of interactions of destination economic, ecological and socio-cultural environment, which has specific structure and functions and complex systems that have contacted with environmental ongoing matter, energy and information. This article discusses the complex dynamic systems where changes come from the survival of tourism and the formation of the ecological environment, that is, the movement between the ecotourism systems and environmental ecosystems. System is a complex system of tourism tourist, tourist destinations and travel channel linking both of them. Ecosystem is the system of organic complexes and environment containing all the physical factors, which is consist of both a tourist attraction, but also its surroundings, and it is a fundamental part of the sustainable development of tourism system. From an ecological perspective, the ecotourism system is actual a special system composed of environment organic complexes (including tourists, local residents and tour operators) and the environment, which must have general properties of ecosystem ecology, following the basic principles. The above two systems are coordinated with tourism management and achieve coordinated development of tourist attractions, destinations ecological environment, and achieve balance and enhance between tourism system and environmental ecosystems. Achieving a balance of tourism ecosystem is an important point to achieve sustainable development of ecotourism. The balance of tourism ecosystem refers to the tourist destination of this "Nature - Society - Economy" complex ecosystem dynamics in the process of development maintaining its relative stable and orderly a state. The external performance 
is the benefit of ecotourism society, economic and tourism unity raising: tourism destination meet the needs of economic development, and from the present to future periods it could improve the standard of living and quality of life for community residents tourist destination; It meets the growing needs of tourists and tourism development needs, providing high quality travel experience to increase tourists; It maintains and improve environmental quality as a tourist destination resources (including natural, human and cultural environment factors); It achieves continuous optimization of tourism ecosystem to achieve a higher level of equilibrium.

\section{THE EXPLORATION ANALYSIS OF SUSTAINABLE DEVELOPMENT OF NATURE RESERVE.}

We can't take the expense of natural resources to seek rapid economic and social development, that is, to achieve the protection in development of ecological tourism and at the overall construction time, we should cultivate new growth points, namely to achieve development in the protection.

We should fully grasp further awareness and understanding of the features and connotation of ecotourism. Ecotourism substantive knowledge and understanding should be based on a thorough grasp of the ecotourism. That is, the essence of eco-tourism should to return to nature and the protect nature, having coordinate closely with social, economic, ecological thinking together to achieve sustainable development, reflecting the principle of harmony between man and nature, tourism and environmental development: We should learn further awareness and understanding of the nature and meaning of ecotourism. Ecotourism has a natural, protection, participation, and the popularity of high-grade, planning and professional and other features.

We should further increase the eco-tourism resources and environmental protection, implementing protective development of ecological resources on the based of effective controlling on the ecotourism environment. Environment and resources are the basis for the existence and development of ecotourism which play an important role in the ecotourism. Firstly, we should further clarify the role and importance of eco-tourism environment in eco-tourism system (including ecotourists, eco-tourism resources, ecotourism and eco-tourism environment), and on the basis of the understanding of eco-tourism on the environment, we should understand the ecology tourism environment has the resources, comprehensive, limited capacity and other characteristics; secondly, We should identify ecotourism environment and select the appropriate ways and means to control.
We should increase investment and policy support for ecotourism facilities to achieve equipments updated, improving service levels, and further strengthen ecotourism management science. We have established the goal of ecotourism and sustainable development, and the urgent need is to increase investment and policy support for ecotourism facilities to achieve equipments updated, improving service levels. Scientific and standardized management mechanism is the fundamental guarantee for the development of ecotourism, which should have a positive nteractions between government departments, tourism enterprises, tourists and tourist communities. To make the concept of popular eco-tourism accepted by people, we need to emphasize scientific management ecotourism.

Strengthening participatory eco-tourism, and constantly improving the tourism structure. We should change impact from the traditional travelling ideason people's behavior, increasing optional choices and active participation awareness. In its own characteristics and advantages on the basis of understanding and positioning, it should constantly improve the tourism structure to achieve true popular tours.

\section{CONCLUSIONS.}

The current new model of sustainable development of eco-tourism is having fundamental changes on traditional model in tourism development, and its establishment and development has important value and meaning on properly treating human and natural resources and the environment and ecological and socio-economic. We should be on the basis of this premise to recognize the reality of China's sustainable development and the development of eco-tourism, and take appropriate actions and measures to achieve our goal of sustainable eco-tourism development.

\section{References}

[1] Niu Jiang. Interest Nature Reserve ecotourism management stakeholder analysis[D]. Beijing Forestry University, 2007.

[2] Li Junqing ecotourism management of nature reserves and Sustainable Development [J] Beijing Forestry University, 2000, 04: 126-127.

The basic principle

[3] Wang Qiu Lian. Ecotourism Management Plan Nature Reserve [J] Urban Environment \& Urban Ecology, 2003, 06: 40-41.

[4] Wang Zuliang. [J] National Institute of Forestry Administration, 2007, $04: 53-57+60$.

[5] He Zhaohe. Nature Reserve of eco tourism development problems and countermeasures [J] environment, 2007, 01: 253-256.

[6] Chen Xiaoqing. To investigate the development of ecotourism Nature Reserve[J] Problems of Forestry Economics, 2001, 04: 216-218.

[7] Zhang Wei. Eco Tourism Nature Reserve [J] Finance Science, 2002, S2: 386-387. 